\title{
Undertreated Hypertension and its Implications for Public Health in Nepal: Nationwide Population-Based Survey
}

\author{
Koju R, ${ }^{1}$ Manandhar K, ${ }^{2}$ Risal A, ${ }^{3}$ Steiner TJ, ${ }^{4,5}$ Holen $A,{ }^{6}$ Linde $\mathrm{M}^{4,6}$
}

\author{
${ }^{1}$ Department of Internal Medicine, \\ Dhulikhel Hospital, Kathmandu University School of \\ Medical Sciences, Dhulikhel, Kavre, Nepal \\ ${ }^{2}$ Department of Community Medicine, \\ Kathmandu University School of Medical Sciences, \\ Dhulikhel Hospital, Dhulikhel, Kavre, Nepal \\ ${ }^{3}$ Department of Psychiatry, \\ Dhulikhel Hospital, Kathmandu University School of \\ Medical Sciences, Dhulikhel, Kavre, Nepal \\ ${ }^{4}$ Department of Neuroscience, \\ Norwegian University of Science and Technology, \\ Trondheim, Norway \\ ${ }^{5}$ Division of Brain Sciences, \\ Imperial College London, London, UK \\ ${ }^{6}$ Department of Neurology and Neurophysiology, \\ St Olavs University Hospital, Trondheim, Norway

\section{Corresponding Author} \\ Rajendra Koju \\ Department of Internal Medicine, \\ Dhulikhel Hospital, Kathmandu University School \\ of Medical Sciences, Dhulikhel, Kavre, Nepal \\ E-mail: rajendrakoju@gmail.com

\section{Citation}

Koju R, Manandhar K, Risal A, Steiner TJ, Holen $A$, Linde M. Undertreated Hypertension and its Implications for Public Health in Nepal: Nationwide Population-Based Survey. Kathmandu Univ Med J 2015;49(1):3-7.

\section{ABSTRACT}

\section{Background}

Hypertension (HTN), a major risk factor for cardiovascular diseases (CVDs), is a substantial global public health problem. Occasional studies indicate a high prevalence of HTN in the Nepalese population, but no nationwide population-based data exist so far. We opportunistically used a survey of major disorders of the brain in Nepal to measure blood pressure (BP) in participants selected randomly from the adult general population.

\section{Objective}

To establish the prevalence of elevated BP (eBP), and factors associated with it, regardless of any antihypertensive therapy being taken. We took this to be indicative of unmet health-care need.

\section{Method}

This was a cross-sectional study, conducted by unannounced household visits, employing multistage random cluster sampling. To achieve representativeness, 15 districts out of 75 in the country were investigated: one district from each of the three physiographic divisions in each of the five development regions of Nepal. One adult aged 18-65 years was selected from each household and interviewed by structured questionnaire. BP was recorded in a standardised manner by digital device (Microlife 3BM1-3 ${ }^{\circledR}$ ).

Result

From 2,109 eligible households, 2,100 adults (99.6\%) participated. The prevalence of eBP ( $>140 / 90 \mathrm{mmHg}$ on $\geq 2$ readings) was found to be $15.1 \%$. Multivariate logistic regression showed significant and independent associations with demographic variables (higher age, male gender), with life-style factors (daily alcohol consumption, $\mathrm{BMI} \geq 25$ ), and with living at high altitude ( $\geq 2000 \mathrm{~m}$ ).

\section{Conclusion}

In the context of the survey we could not collect data on antihypertensive therapy being taken but, clearly, whatever this might have been, it was failing to meet treatment needs. Almost one in six adults met criteria for hypertension, carrying risk implications for CVDs and their substantial public-health consequences. Two remediable associated factors were identified, although in a cross-sectional survey we could not prove causation.

\section{KEY WORDS}

Cardiovascular disease, coronary artery disease, hypertension 


\section{INTRODUCTION}

Hypertension (HTN) is a global public health problem contributing substantially to the burden of noncommunicable diseases. ${ }^{1,2}$ It is one of the major risk factors for cardiovascular diseases (CVDs), ${ }^{1}$ from which an estimated 17.3 million people worldwide die each year, a number expected to rise to 23.3 million by $2030 .{ }^{1}$ Over $80 \%$ of these deaths occur in low- and middle-income countries, and the suggestion has been made that HTN is significantly more prevalent in low-income countries. ${ }^{1}$ However, good population-based studies are resource-demanding and not easily performed in these countries, which tend to have poor infrastructure and regions of difficult access.

Nepal is a low-income country, with approximately 30 million people. Geographically, ethnically and culturally diverse ${ }^{3}$ its landscape spans three physiographic divisions: Mountain (which includes the Himalayan peaks), Hill (essentially the Himalayan foothills) and Terai (plains up to $200 \mathrm{~m}$ above sea level). From East to West, the country is divided into five developmental regions. There were very limited data on HTN or CVDs in Nepal until decades ago. ${ }^{4}$ Current estimates of the prevalence of HTN, in the range $18.8-41.8 \%$, are based on diverse populations from different localities and various points of time. ${ }^{1} \mathrm{~A}$ study in Dharan, a town of Eastern Nepal, found the prevalence of HTN to be close to $23 \%^{5}$; a community-based study in rural Kathmandu found it to be $33.8 \%{ }^{6}$; a broader study of HTN, obesity, diabetes and metabolic syndrome in Eastern Nepal found a very similar $33.9 \% .^{7}$ While these studies indicated a high prevalence of HTN in the Nepalese population, none were nationwide and there has been no publication exploring HTN on a national level.

We were able to take advantage of a carefully-conducted nationwide survey of major disorders of the brain in adult general population of Nepal, carried out during May $2013 .{ }^{8}$ One of the variables of interest was blood pressure (BP). We therefore sought to establish the prevalence of elevated BP (eBP), and factors associated with it. In the context of this survey we could not collect data on any antihypertensive therapy being taken, but took the view that, whatever this might have been, it was failing to meet treatment needs. Therefore, the prevalence of eBP (treated or not) was indicative of unmet health-care need.

\section{METHODS}

The study was part of a nationwide epidemiological survey addressing major disorders of the brain in Nepal, of which the methods have been published in detail. ${ }^{8,9}$ It was approved by the Nepal Health Research Council (NHRC), the Institutional Review Committee of Kathmandu University School of Medical Sciences, Dhulikhel Hospital (IRC-KUSMS), and the Central Regional Committee for Health and Research Ethics in Norway.

\section{Study Design}

The survey was a cross-sectional study, conducted by unannounced household visits, employing multistage random cluster sampling. To achieve representativeness, 15 districts out of 75 in the country were sampled: one district from each of the three physiographic divisions (Mountain, Hill and Terai) in each of the five development regions of Nepal (Fig. 1). We ensured that numbers sampled from each of the physiographic divisions were proportional to populations within those divisions. One adult aged 1865 years was selected from each included household and interviewed by structured questionnaire. We excluded immigrants and those with major physical or mental health disorders.

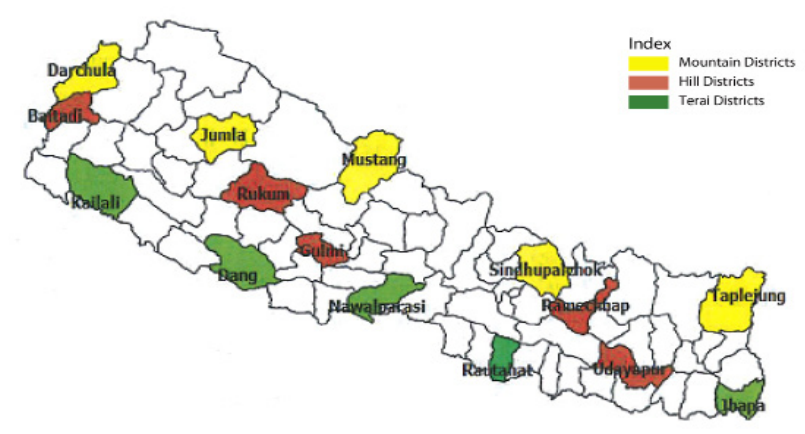

All data were collected within the month of May, 2013.

\section{Blood pressure measurement}

We used a digital device (Microlife 3BM1-3 ${ }^{\circledR}$ ). The participant sat on the floor to ensure uniformity since most Nepalese homes did not have a chair available. We took two readings from the right arm, with a rest in between. If either reading was above $140 / 90 \mathrm{~mm} \mathrm{Hg}$, the measurement was repeated after a further two minutes of rest. We used the averages of the systolic and diastolic measurements. Then we categorized the BP according to the criteria of the Joint National Committee $7^{\text {th }}$ report (JNC7). ${ }^{10}$ All measurements with $\mathrm{SBP} \geq 140$ or $\mathrm{DBP} \geq 90$ or $\mathrm{SBP}>140$ and $\mathrm{DBP}>90 \mathrm{mmHg}$ were considered eBP; rest were all considered normotensives.

\section{Data analysis}

Analyses were carried out using the Statistical Package for Social Science (IBM SPSS Statistics 21). Prevalence of eBP was calculated as percentages with $95 \%$ confidence intervals (Cls). We used bivariate and multivariate logistic regression to evaluate associations between eBP and candidate factors, calculating odds ratios (ORs) and adjusted ORs (AORs) respectively. The following variables were included in the analytical models: gender, age, urban vs rural habitation, household altitude ( $\geq 2000$ vs $<2000 \mathrm{~m}$ ), 
smoking tobacco (yes vs no), alcohol intake (sometimes or daily vs never), and body mass index (BMI; underweight [BMI <18.5] or overweight/obese [BMI $\geq 25]$ vs normal [BMI $=18.5-24.9]$. To serve as the dependent variable in the logistic regression, BP was categorized as elevated (systolic $\geq 140 \mathrm{~mm} \mathrm{Hg}$ and/or diasystolic $\geq 90 \mathrm{~mm} \mathrm{Hg}$ ) or nonelevated (systolic <140 mm Hg and diasystolic <90 mm Hg).

\section{RESULTS}

We recruited 2,100 participants from 2,109 eligible households (participation rate 99.6\%), 1,239 (59.0\%) female, 831 (41.0\%) male, mean age $34.4 \pm 12.8$ years. Most $(1,328 ; 63.3 \%)$ were from rural areas.

Mean systolic and diastolic blood pressures were 121.7 \pm 14.9 $\mathrm{mm} \mathrm{Hg}$ and $79.6 \pm 10.7 \mathrm{~mm} \mathrm{Hg}$ respectively. We found eBP in 317 participants $(15.1 \%$ [95\% Cl 13.6 - 16.6\%]; males: 21.7\%; females: 10.5\%). According to JNC7 criteria [10], 229 (10.9\%) would be classified as Stage I hypertension and $88(4.2 \%)$ as Stage II hypertension. However, of those we considered not to have eBP, a further 915 (43.6\%) met JNC7 criteria for pre-hypertension.

Table 1 shows variation in prevalence of eBP by physiographic division. Greatest was in the Mountain division (29.5\% [95\% Cl 22.6 - 36.4\%]), highly significantly different from the Terai. There was some variation across the developmental regions: prevalence was highest in the Western region (21.0\% [95 \% Cl 17.1 - 24.9\%]), followed by the Central (16.9\% [95\% Cl $13.3-20.5 \%])$, and lowest in the Far-Western (10.5\% [95\% Cl 7.6 - 13.4\%]).

Table 1. Prevalence of elevated blood pressure (eBP) by physiographic region

\begin{tabular}{lcccc}
$\begin{array}{l}\text { Physiographic } \\
\text { division }\end{array}$ & $\mathbf{N}$ & $\begin{array}{c}\text { eBP prevalence } \\
\mathrm{n}(\%)\end{array}$ & $\begin{array}{c}\text { OR* } \\
{[95 \% \mathrm{Cl}]}\end{array}$ & $\mathbf{p}$ \\
\hline Mountain & 170 & $50(29.5)$ & $2.60[1.8-3.8]$ & $<0.001$ \\
\hline Hill & 930 & $130(14.0)$ & $1.02[0.8-1.3]$ & 0.86 \\
\hline Terai & 1,000 & $137(13.7)$ & Reference & \\
\hline
\end{tabular}

* Odds ratios (ORs) calculated by bivariate analysis

The results of bivariate and multivariate logistic regression analyses are set out in Table 2, and confirm the strong male propensity for eBP (OR 2.4; AOR 1.8). The prevalence of eBP increased with age, peaking in the oldest age group 60-65 years (OR 15,9; AOR 14.0. Bivariate analysis showed that the prevalence of eBP was positively associated with smoking and alcohol consumption at least once a week and highly associated with daily alcohol consumption. It was also associated with $\mathrm{BMI} \geq 25$. Multivariate analysis confirmed that all these factors except smoking were independently associated with eBP (Table 2).
Table 2. Associations with elevated blood pressure (eBP) (bivariate and multivariate logistic regression analyses)

\begin{tabular}{|c|c|c|c|c|c|c|}
\hline \multirow[t]{2}{*}{ Variable } & \multirow[t]{2}{*}{$N$} & \multirow{2}{*}{$\begin{array}{c}\text { eBP } \\
\text { prevalence } \\
\mathrm{n}(\%)\end{array}$} & \multicolumn{2}{|c|}{$\begin{array}{c}\text { Bivariate } \\
\text { analysis }\end{array}$} & \multicolumn{2}{|c|}{$\begin{array}{l}\text { Multivariate } \\
\text { analysis }\end{array}$} \\
\hline & & & $\begin{array}{c}\text { OR } \\
{[95 \% \mathrm{Cl}]}\end{array}$ & $p$ & $\begin{array}{c}\text { AOR } \\
{[95 \% \mathrm{Cl}]}\end{array}$ & $p$ \\
\hline \multicolumn{7}{|l|}{ Gender } \\
\hline male & 861 & $187(21.7)$ & $\begin{array}{c}2.4[1.9- \\
3.1]\end{array}$ & $<0.001$ & $\begin{array}{c}1.8[1.4- \\
2.4]\end{array}$ & $<0.001$ \\
\hline female & 1,239 & $130(10.5)$ & Reference & & & \\
\hline
\end{tabular}

Age group (years)

\begin{tabular}{|c|c|c|c|c|c|c|}
\hline $18-19$ & 137 & $6(4.4)$ & Reference & & & \\
\hline $20-24$ & 295 & $21(7.1)$ & $\begin{array}{c}1.7[0.7- \\
4.2]\end{array}$ & 0.28 & $\begin{array}{c}1.7[0.7- \\
4.4]\end{array}$ & 0.25 \\
\hline $25-29$ & 318 & $20(6.3)$ & $\begin{array}{c}1.5[0.6- \\
3.7]\end{array}$ & 0.42 & $\begin{array}{c}1.3[0.5- \\
3.3]\end{array}$ & 0.61 \\
\hline $30-34$ & 305 & 35 (11.5) & $\begin{array}{c}2.8[1.2- \\
6.9]\end{array}$ & & $\begin{array}{c}2.4[1.0- \\
6.0]\end{array}$ & 0.021 \\
\hline $35-39$ & 257 & $36(14.0)$ & $\begin{array}{c}3.6[1.5- \\
8.7]\end{array}$ & 0.005 & $\begin{array}{c}2.9[1.2- \\
7.2]\end{array}$ & 0.002 \\
\hline $40-44$ & 220 & 43 (19.5) & $\begin{array}{c}5.3[2.2- \\
12.8]\end{array}$ & $<0.001$ & $\begin{array}{c}4.1 \text { [1.6- } \\
10.0]\end{array}$ & 0.001 \\
\hline $45-49$ & 152 & $32(21.1)$ & $\begin{array}{c}5.8[2.4- \\
14.4]\end{array}$ & $<0.001$ & $\begin{array}{c}4.9[2.0- \\
2.4]\end{array}$ & $<0.001$ \\
\hline $50-54$ & 170 & $40(23.5)$ & $\begin{array}{c}6.7[2.7- \\
16.4]\end{array}$ & $<0.001$ & $\begin{array}{c}5.1[2.0- \\
12.6]\end{array}$ & $<0.001$ \\
\hline $55-59$ & 113 & $28(24.8)$ & $\begin{array}{c}7.2[2.9- \\
18.1]\end{array}$ & $<0.001$ & $\begin{array}{c}6.4[2.5- \\
16.3]\end{array}$ & $<0.001$ \\
\hline $60-65$ & 133 & $56(42.1)$ & $\begin{array}{c}15.9[6.5- \\
38.6]\end{array}$ & $<0.001$ & $\begin{array}{l}14.0 \\
{[5.7-} \\
34.5]\end{array}$ & $<0.001$ \\
\hline
\end{tabular}

\begin{tabular}{|c|c|c|c|c|c|c|}
\hline \multicolumn{7}{|c|}{ Habitation } \\
\hline urban & 772 & 115 (14.9) & $\begin{array}{c}0.97 \text { [0.8- } \\
1.3]\end{array}$ & 0.85 & $\begin{array}{c}1.1[0.9- \\
1.6]\end{array}$ & 0.32 \\
\hline rural & 1,328 & $202(15.2)$ & Referent & & & \\
\hline \multicolumn{7}{|c|}{ Altitude of household } \\
\hline$\geq 2000 \mathrm{~m}$ & 470 & $88(18.7)$ & $\begin{array}{c}1.4[1.1- \\
1.8]\end{array}$ & 0.013 & $\begin{array}{c}1.3[0.9- \\
1.9]\end{array}$ & 0.06 \\
\hline$<2000 \mathrm{~m}$ & 1,630 & $229(14.0)$ & referent & & & \\
\hline \multicolumn{7}{|l|}{ Smoking } \\
\hline yes & 487 & $90(18.5)$ & $\begin{array}{c}1.4[1.1- \\
1.8]\end{array}$ & 0.018 & $\begin{array}{c}0.8[0.6- \\
1.0]\end{array}$ & 0.070 \\
\hline no & 1,613 & $227(14.1)$ & referent & & & \\
\hline \multicolumn{7}{|c|}{ Alcohol consumption } \\
\hline never & 1,512 & $178(11.8)$ & Referent & & & \\
\hline $\begin{array}{l}\text { some- } \\
\text { times }\end{array}$ & 415 & $89(21.4)$ & $\begin{array}{c}2.1[1.5- \\
2.7]\end{array}$ & $<0.001$ & $\begin{array}{c}1.8[1.3- \\
2.4]\end{array}$ & 0.001 \\
\hline daily & 173 & $50(28.9)$ & $\begin{array}{c}3.1[2.1- \\
4.4]\end{array}$ & $<0.001$ & $\begin{array}{c}2.1 \text { [1.4- } \\
3.2]\end{array}$ & 0.001 \\
\hline \multicolumn{7}{|c|}{ Body mass index } \\
\hline normal & 1,398 & $178(12.7)$ & Referent & & & \\
\hline $\begin{array}{l}\text { under- } \\
\text { weight }\end{array}$ & 279 & $30(10.8)$ & $\begin{array}{c}0.8[0.5- \\
1.2]\end{array}$ & 0.36 & $\begin{array}{c}0.9[0.6- \\
1.4]\end{array}$ & 0.57 \\
\hline $\begin{array}{l}\text { over- } \\
\text { weight }\end{array}$ & 423 & $109(25.8)$ & $\begin{array}{c}2.4[1.8- \\
3.1]\end{array}$ & $<0.001$ & $\begin{array}{c}2.3[1.7- \\
3.1]\end{array}$ & $<0.001$ \\
\hline
\end{tabular}




\section{DISCUSSION}

This first nationwide population-based study in Nepal to estimate the adult prevalence of eBP had multiple strengths. We recruited a large sample $(2,100)$ from the whole country, inclusive of its ethnic, cultural and geographical diversities, engaged participants in face-to-face interviews for better data quality and strongly promoted representativeness through a participation rate of $>99 \%$. We measured BP in participants' own homes, using a standardised procedure and similar devices. We collected all data within a month. The principal limitation was the cross-sectional design of the study, so that we could not establish causation in any associations between eBP and other variables.

The overall prevalence of eBP was $15.1 \%$ - almost one in six adults aged 18-65 years. Prevalence of eBP was positively associated with age, male gender, alcohol consumption, $\mathrm{BMI} \geq 25$ and altitude $\geq 2000 \mathrm{~m}$. Many studies, including two in Nepal, 5,17 have reported that the prevalence of HTN increases with age and there is a very large literature on the biology of this association. ${ }^{17,18}$ We observed the agerelated increase in eBP prevalence, occurring in both genders, was more than ten-fold between 18-19 and 60-65 years.

Studies elsewhere have also shown HTN to be more prevalent among men than women, ${ }^{11-13}$ although there are some with the opposite finding or showing no gender difference. ${ }^{14-16}$ A preponderance of HTN in men may be explained by differential risk factors between women and men across populations. The positive association that we observed of eBP with male gender is in line with earlier regional studies in Nepal. ${ }^{6,17}$ Culturally, men in Nepal may be more exposed than women to life-style factors such as alcohol consumption and tobacco smoking. These are modifiable factors but, although the former at least showed a strong and progressive association with eBP, in this cross-sectional study we could not demonstrate any causal link to identify them as risk factors. Alcohol consumption is an important life-style habits that is positively associated with HTN. ${ }^{17,20}$ We found that daily alcohol consumers were three times more likely to have eBP than teetotallers. Cigarette smoking may increase BP by increasing sympathetic activity. ${ }^{19}$ It is important to point out that our data, similar to other studies, have shown that smokers have not significantly higher BP than nonsmokers. This lack of association may be explained by the fact that we analysed data only from current smokers and not those who might have changed their smoking habits after identification of HTN.

Being overweight or obese is also an important risk factor for HTN, ${ }^{21}$ because of the adverse metabolic effects on BP. ${ }^{18}$ In line with other studies in Nepal, ${ }^{5,17}$ we found BMI $\geq 25$ $\mathrm{kg} / \mathrm{m}^{2}$ to be positively associated with eBP.

Finally, we found a higher prevalence of eBP in people residing at altitudes of $\geq 2000 \mathrm{~m}$. Studies of the relationship between high altitude and hypertension in a populationbased study are rather rare. Hypoxia is one possible explanation for this association: chronic hypoxia causes marked activation of the sympathetic nervous system in healthy humans and also increased arterial pressure. ${ }^{22}$

\section{Implications for health and health care}

Whereas the overall prevalence of eBP was $15.1 \%$, two thirds of these cases (10.9\%) would be classified according to JNC7 criteria as Stage I hypertensive and the remainder (4.2\%) as Stage II hypertensive. Crucially, these findings were despite any antihypertensive therapy that was being made available, and are therefore a measure of the extent to which such therapy was not achieving its public-health objective (ie, of unmet health-care need). The importance of this in public-health terms lies in the substantial health risks ensuing from HTN, including and especially those leading to CVDs.

The significantly higher number of eBP cases in the Himalayas and Hills probably indicate the necessity of treatment or educational campaign regarding the importance of contact with the physician in the high altitude regions. Similarly, the role of modifiable risk factors (more importantly substances of abuse and other dietary factors) in the occurrence of HTN also needs particular emphasis with the public health point of view.

\section{CONCLUSION}

Almost one in six adults in this survey had eBP, meeting JNC7 criteria for hypertension. The survey could not collect data on any antihypertensive therapy being taken but, whatever this might have been, it was failing to meet treatment needs. This level of untreated or inadequately treated eBP carries major risk implications for CVDs, and represents a substantial threat to public health. The study therefore discloses and gives a measure of unmet healthcare need in Nepal. Two remediable associated factors were identified, although in a cross-sectional survey we could not prove causation.

\section{ACKNOWLEDGEMENTS}

This project has been funded by grants from Samarbeidsorganet, which is the Norwegian name for the Liaison Committee between the Central Norway Regional Health Authority and the Norwegian University of Science and Technology (NTNU). The study is a part of a broader research collaboration between NTNU Department of Neuroscience, Kathmandu University School of Medical Sciences (KUSMS) and Lifting The Burden, a UK-registered non-governmental organization directing the Global Campaign against Headache in official relations with the World Health Organization. 


\section{REFERENCES}

1. WHO. Global status report on communicable diseases. 2010.

2. Kearney PM, Whelton M, Reynolds K, Muntner P, Whelton PK, He J. Global burden of hypertension: analysis of worldwide data. Lancet 2005; 365 (9455):217-223. doi:10.1016/s0140-6736(05)17741-1

3. The World Factbook. Central Intelligence Agency, Office of Public Affairs. https://www.cia.gov/library/publications/the-worldfactbook/ geos/np.html. Accessed 14 Jan 2013

4. Pandey MR. Hypertension in Nepal. Bibl Cardiol 1987;(42):68-76.

5. Vaidya A, Pokharel PK, Karki P, Nagesh S. Exploring the iceberg of hypertension: a community based study in an eastern Nepal town. Kathmandu Univ Med J (KUMJ) 2007;5(3):349-59.

6. Vaidya A, Pathak RP, Pandey MR. Prevalence of hypertension in Nepalese community triples in 25 years: a repeat cross-sectional studyin rural Kathmandu. Indian Heart J 2012;64(2):128-131. doi:10.1016/s0019-4832(12)60045-5

7. Sharma SK, Ghimire A, Radhakrishnan J, Thapa L, Shrestha NR, Paudel $\mathrm{N}$ et al. Prevalence of hypertension, obesity, diabetes, and metabolic syndrome in Nepal. Int J Hypertens 2011:821971. doi:10.4061/2011/821971

8. Manandhar K, Risal A, Steiner TJ, Holen A, Koju R, Linde M. Estimatingthe prevalence and burden of major disorders of the brain in Nepal: methodology of a nationwide population-based study. $J$ Headache Pain 2014;15:52. doi:10.1186/1129-2377-15-52

9. Risal A, Manandhar K, Steiner TJ, Holen A, Koju R, Linde M. Estimating prevalence and burden of major disorders of the brain in Nepal: cultural, geographic, logistic and philosophical issues of methodology. J Headache Pain 2014;15:51. doi:10.1186/1129-2377-15-51.

10. Chobanian AV, Bakris GL, Black HR, Cushman WC, Green LA, Izzo JL et al. Seventh report of the Joint National Committee on Prevention, Detection, Evaluation, and Treatment of High Blood Pressure. Hypertension 2003;42(6):1206-1252.doi:10.1161/01. HYP.0000107251.49515.c2

11. Shanthirani CS, Pradeepa R, Deepa R, Premalatha G, Saroja R, Mohan V. Prevalence and risk factors of hypertension in a selected South Indian population--the Chennai Urban Population Study. J Assoc Physicians India 2003;51:20-27
12. Stein AD, Stoyanovsky V, Mincheva V, Dimitrov E, Hodjeva D, Petkov A et al. Prevalence, awareness, treatment and control of hypertension in a working Bulgarian population. Eur J Epidemiol 2000;16(3): 265-270

13. Jenei Z, Pall D, Katona E, Kakuk G, Polgar P. The epidemiology of hypertension and its associated risk factors in the city of Debrecen, Hungary. Public Health 2002;116(3):138-144. doi:10.1038/ sj.ph.1900840

14. Choi KM, Park HS, Han JH, Lee JS, Lee J, Ryu OH et al. Prevalence of prehypertension and hypertension in a Korean population: Korean National Health and Nutrition Survey 2001. J Hypertens 2006 24(8):1515-1521. doi:10.1097/01.hjh.0000239286.02389.0f

15. Ahmad K, Jafar TH. Prevalence and determinants of blood pressure screening in Pakistan. J Hypertens 23 (11):1979-84.

16. 16. Onal $A E$, Erbil S, Ozel S, Aciksari K, Tumerdem $Y$ (2004) The prevalence of and risk factors for hypertension in adults living in Istanbul. Blood Press 2005;13 (1):31-6.

17. Manandhar K, Koju R, Sinha NP, Humagain S. Prevalence and associated risk factors of hypertension among people aged 50 years and more in Banepa Municipality, Nepal. Kathmandu Univ Med J (KUMJ) 2012;10(39):35-8.

18. Erem C, Yildiz R, Kavgaci H, Karahan C, Deger O, Can G et al. Prevalence of diabetes, obesity and hypertension in a Turkish population (Trabzon city). Diabetes Res Clin Pract 2001;54(3):203-8.

19. Kong C, Nimmo L, Elatrozy T, Anyaoku V, Hughes C, Robinson S et al. Smoking is associated with increased hepatic lipase activity, insulin resistance, dyslipidaemia and early atherosclerosis in Type 2 diabetes. Atherosclerosis 2001;156 (2):373-8.

20. Ibekwe R. Modifiable Risk factors of Hypertension and Sociodemographic Profile in Oghara, Delta State; Prevalence and Correlates. Annals of medical and health sciences research 2015;5 (1):71-77. doi:10.4103/2141-9248.149793

21. Kunz I, Schorr U, Klaus S, Sharma AM. Resting metabolic rate and substrate use in obesity hypertension. Hypertension 2000; 36 (1): 26-32.

22. Calbet JA. Chronic hypoxia increases blood pressure and noradrenaline spillover in healthy humans. J Physiol 2003;551(1) pp 379-86. 